\title{
Multidimensional finite element simulations of the diffusion and trapping of hydrogen in Plasma- Facing Components including thermal expansion
}

\author{
Sofiane Benannoune ${ }^{1}$, Yann Charles ${ }^{1}$, Jonathan Mougenot ${ }^{1}$, Monique Gaspérini ${ }^{1}$ \\ and Greg De Temmerman ${ }^{2}$ \\ ${ }^{1}$ Université Paris 13, Sorbonne Paris Cité, LSPM, CNRS UPR 3407, 99 avenue Jean-Baptiste Clément, \\ 93430 Villetaneuse \\ ${ }^{2}$ ITER Organization, Route de Vinon-sur-Verdon, CS 90046, 13067 St. Paul Lez Durance Cedex, \\ France
}

E-mail: jonathan.mougenot@1spm.cnrs.fr

Received 21 june 2019

Accepted for publication $\mathrm{xxxxxx}$

Published xxxxxx

\begin{abstract}
This study is focused on tritium retention and permeation through a $316 \mathrm{~L}$ stainless steel diagnostic first wall during plasma operations in ITER. A set of data for migration properties are proposed by adjusting these values to fit a simulation with experimental results. A reactive-diffusion model coupled with mechanical field, solved on 3DS Abaqus finite element software, is applied to estimate tritium migration. The interest of $2 \mathrm{D}$ simulations compared to 1D simulations are shown and the role of thermal expansion on plastic deformation and trap creation is discussed.
\end{abstract}

Keywords: FEM, Abaqus, Reaction-diffusion code, Stainless steel

\section{Introduction}

Understanding the diffusion and trapping of hydrogen isotopes (HI) in plasma facing components (PFC) is an important issue for future fusion device operations. For such a purpose, specific macroscopic rate equations (MRE) codes [1-3] were developed to solve both diffusion and full kinetic trapping of $\mathrm{HI}$ in metals, using the McNabb and Foster equation [4]. Numerical simulations based on these codes have shown the important role played by temperature on HI inventory and permeation, so that a particular attention must be paid to the determination of the thermal field, especially for 2D geometries [5]. Furthermore, the stress induced by spatio-temporal temperature variation could impact the HI inventory [6]. In order to understand the thermo-mechanical coupling, a special focus has to be made on the development of numerical models which, beside HI transport and trapping, include the coupled resolution of the thermal and mechanical problem, for 2D and 3D complex geometries.

In this paper, a fully coupled multidimensional and multiphysics MRE code is proposed, based on the generalized transport and trapping temporal equations, the heat equation and the computation of the thermomechanical fields. This tool has been developed based using the 3DS 
Abaqus finite element software and several User Subroutines [7].

In the first section, a set of data for 316L stainless steel diffusion and trapping properties is proposed based on simulations of experimental data. The plasma-facing surface, called the Diagnostic First Wall (DFW) of the diagnostic port plugs in ITER will be made of $316 \mathrm{~L}(\mathrm{~N})-\mathrm{IG}$ stainless steel. Several simulations are then performed, to model the tritium transport and trapping through the DFW Deuterium-Tritium (D-T) operations tritium retention and permeation predicted with the Abaqus code based on the 2D transient thermal field and trapping resolutions are compared with the 1D equivalent case. Last, the role of thermo mechanical effects will be discussed.

\section{Set of data for migration of tritium in 316L Steel}

Diffusion and recombination coefficients for the $316 \mathrm{~L}$ stainless steel are determined by an inverse identification (based on an iterative process) between simulations and experimental results of tritium depth profiles and permeation flux for 8 specimens (N3, II, F, III, S14, S13, S15 and S16), obtained from [8,9] (4 are homogeneously loaded, with a constant concentration profile over their depth, 4 are nonhomogeneously loaded and therefore have a concentration gradient across their depth).

Fig. 1 illustrates the results obtained with this method. The simulation results have been obtained using the 1D TMAP software [1] considering a single trap with a concentration of 0.08 at.fr. and a detrapping energy of $0.7 \mathrm{eV}$ and for which recombination fluxes are applied on both faces of the sample geometry [10]. The simulated operations are loading, desorption and ageing. The loading consists in the exposure of samples to a given partial pressure of tritium. Desorption were performed by annealing the samples at various temperatures under a flow of argon or in vacuum. For the results presented Fig. 1 the desorption was first started at $400^{\circ} \mathrm{C}$ and after $7 \mathrm{~h}$ the temperature was increased up to $800^{\circ} \mathrm{C}$ in order to remove the majority of the tritium. The ageing was performed by storing the samples for long periods of time ( $\sim$ years) at ambient temperature. The radioactive decay of tritium is taken into account with a halflife of 12.32 years.

The mean diffusion coefficient $D$ and recombination one $k_{r}$ identified from all simulations are:

and

$$
D=8.0 \times 10^{-7} \exp \left(-\frac{0.56}{k T}\right) \mathrm{m}^{2} / \mathrm{s}
$$

$$
k_{r}=2.16 \times 10^{-24} \exp \left(-\frac{0.58}{k T}\right) \mathrm{m}^{4} / \mathrm{s}
$$

with $T$ the temperature $(\mathrm{K})$ and $k$ the Boltzmann constant $\left(\mathrm{eV} . \mathrm{K}^{-1}\right)$. This value of $\mathrm{D}$ is consistent with the values that can be found in the literature (see [11], and Fig. 2), validating the inverse identification approach.
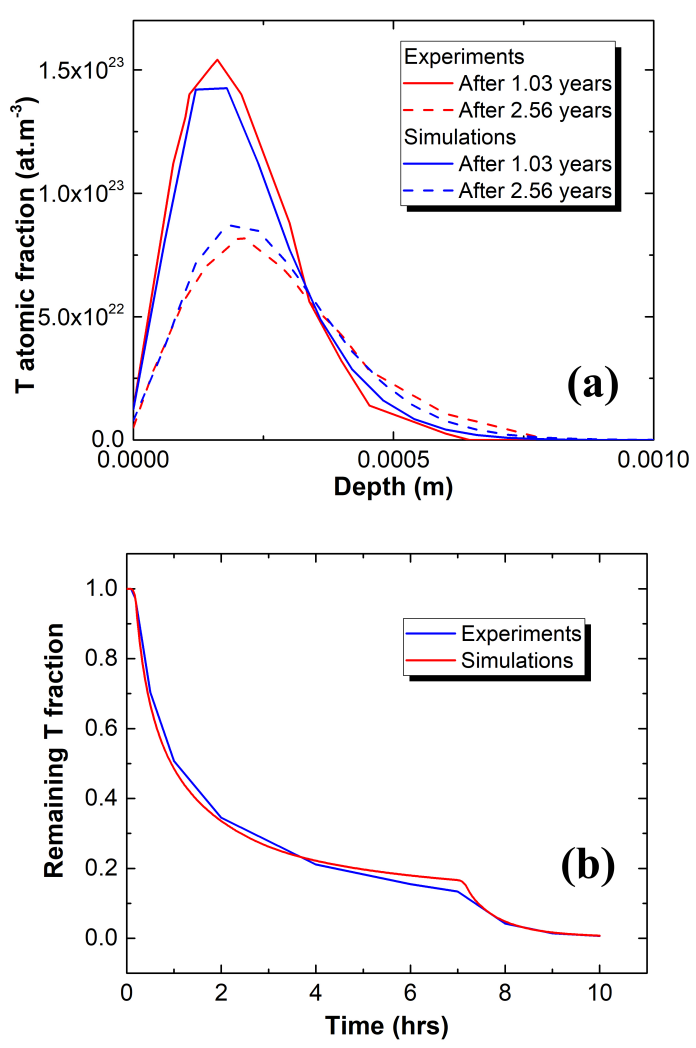

Fig.1. Numerical/experiment confrontations on (a) depth profile and (b) desorption for S14 sample [10].

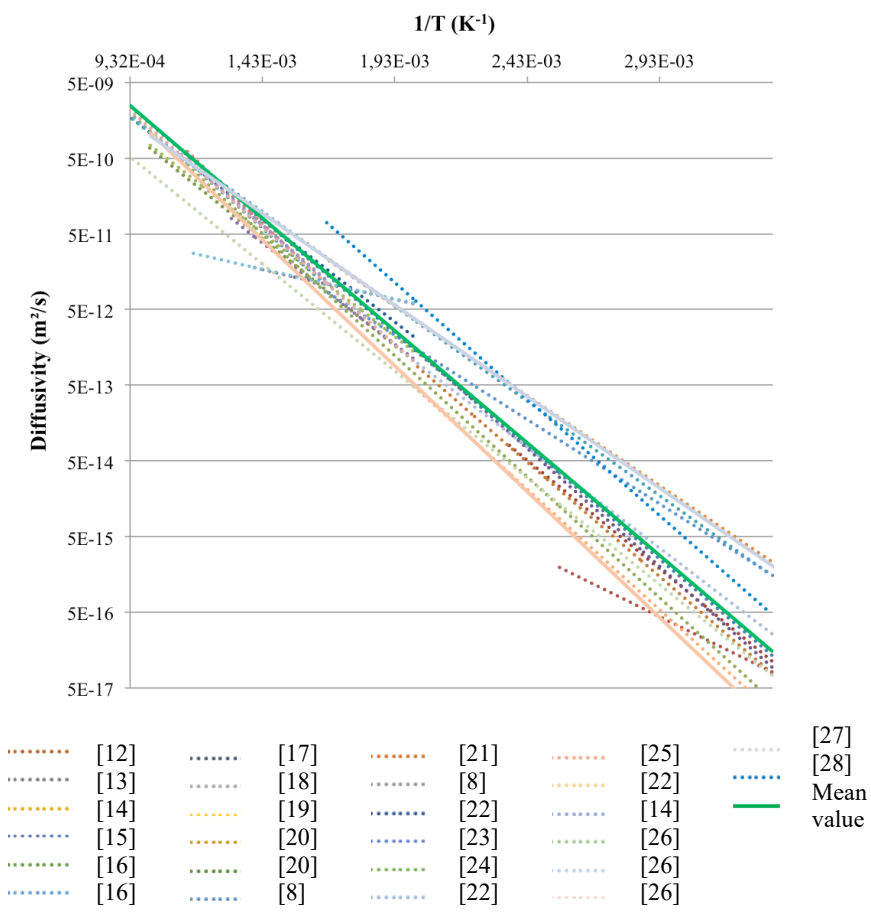

Fig.2.Evolution with the temperature of the mean diffusivity values identified by inverse method (green - see equation 1 ) and the literature data. 


\section{Retention and permeation simulation through DFW}

Simulations of retention and permeation of tritium trough the ITER DFW are performed in 2D with Abaqus software, with specific developments for fusion applications, especially tritium diffusion and trapping; more details on the underlying set of equation might be found in [5,29-31]. Compared to these previous works, the model includes a transient heat equation resolution (with an Abaqus UEL subroutine [32]). It is worth noting that in the present paper, the Ludwing-Soret [33] effect is not taken into account, for we mainly want to point out the effect of the mechanical fields on the permeation process (see bellow, section 4).

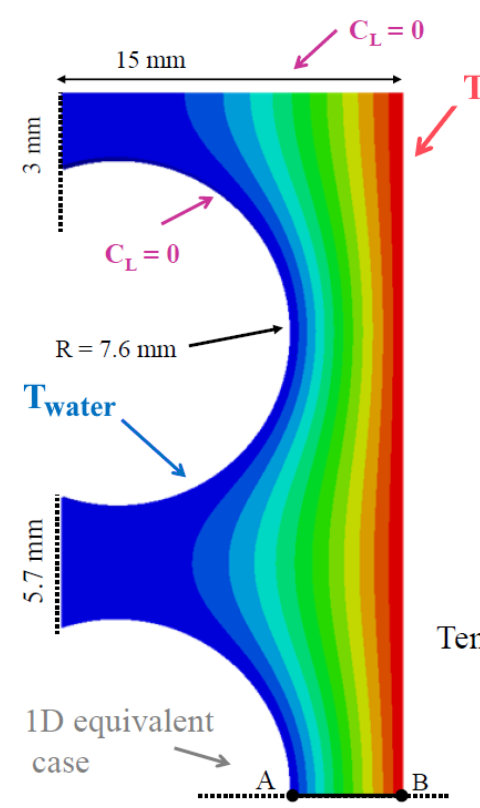

Fig. 3. Geometry, boundary conditions and thermal field during a plasma pulse. For the 1D computations, only the segment $[\mathrm{AB}]$ is considered.

The used geometry is illustrated in Fig. 3 (directly extracted from Catia file), the applied load being defined following the different phases of ITER scenario (see Fig. 4). The first phase corresponds to the plasmas operations: the 13 plasmas pulses of each days are concatenated in 3 days (i.e. the pulse time correspond to 39 effective pulses) due to calculation time cost. The temperature of the cooling tube and the exposed surface (respectively in blue and red on Fig 4) are assumed homogenous on the surface. The tritium implantation is modeled by imposing a solute concentration $C_{L, 0}$ on the exposed surface so that $[34,35]$

$$
C_{L, 0}=\frac{R_{p} \Gamma}{\rho D}
$$

where $\Gamma$ represents the tritium charge-exchange flux which evolves as the temperature (linear/constant/linear) during the plasma operation (up to $2 \times 10^{19} \mathrm{~T} \cdot \mathrm{m}^{-2} \cdot \mathrm{s}^{-1}$ during the plateau),
$R_{p}$ is the mean implantation depth $(13 \mathrm{~nm})$ and $\rho$ is the tungsten density. The diffusion coefficient is assumed to be constant during the cycle (calculated at $503 \mathrm{~K}$ ). A zero concentration is imposed at the top surface (instantaneous desorption). During the baking phase, the temperature is imposed at $513 \mathrm{~K}$ on the boundaries. Assuming that the saturation effect observed in [36] applies for bcc metal, the trap density is multiplied by an ad hoc factor of 2.5 in order to account for the neutron-induced damage.

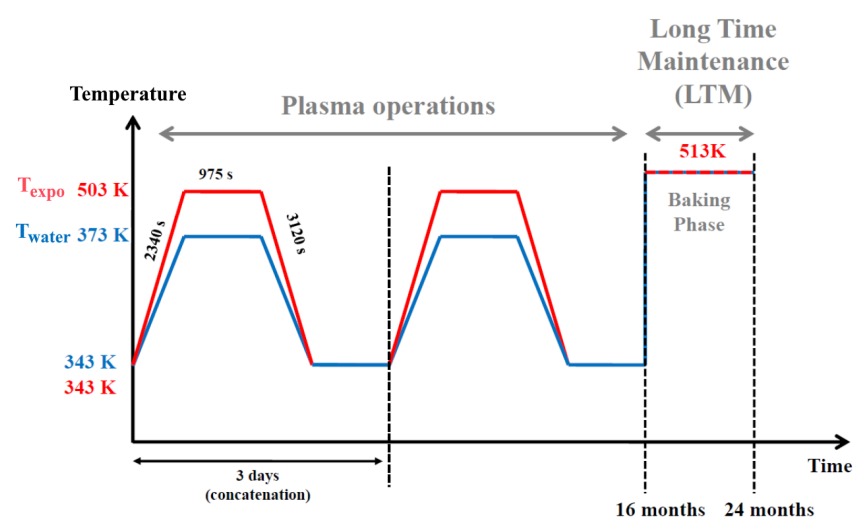

Fig. 4. Scenario \& temperature conditions.

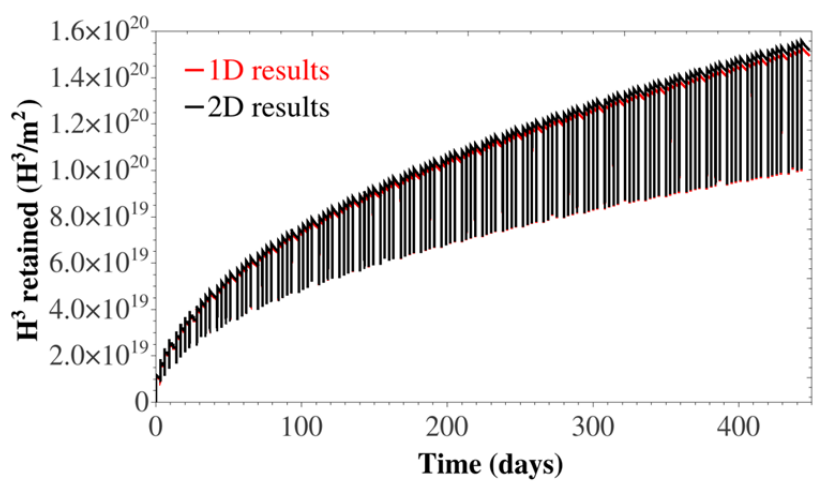

(a)

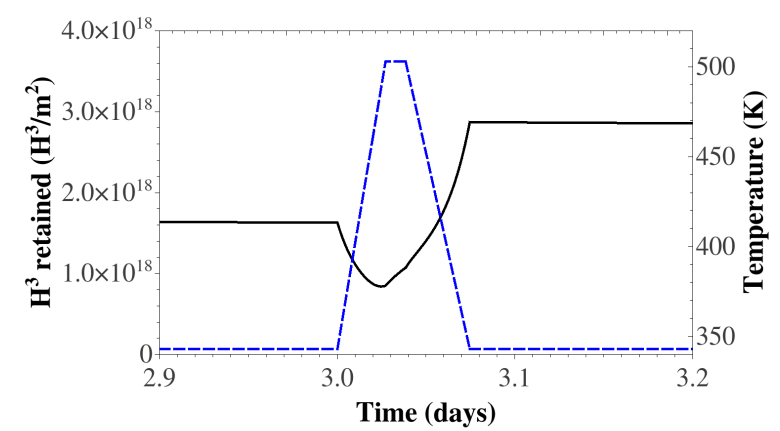

(b)

Fig. 5. Tritium retrained (a) over the time for $1 \mathrm{D}$ (red) and 2D (black) simulations and (b) for a plasma pulse (temperature in dotted line) 


\subsection{Tritium retained during plasma operations}

During the plasma pulse the temperature of the cooling tube surface and the exposed one are different; the maximum induced thermal gradient (which occurs at the middle duration of each pulse and reaches rapidly the equilibrium) is presented on Fig. 3. On Fig. 5 (a) are plotted the evolution of the total retained tritium for the $2 \mathrm{D}$ and the $1 \mathrm{D}$ simulations (see Fig. 3). Both computations are very close, because of the very small tritium penetration depth after the 16 months of plasma operations, exhibiting strong variation with time because of the tritium desorption during the increase of temperature at the pulse beginning as shown on Fig.5 (b). For this kind of configurations and boundary conditions, 1D simulations seems sufficient to model tritium behavior during plasma operations.
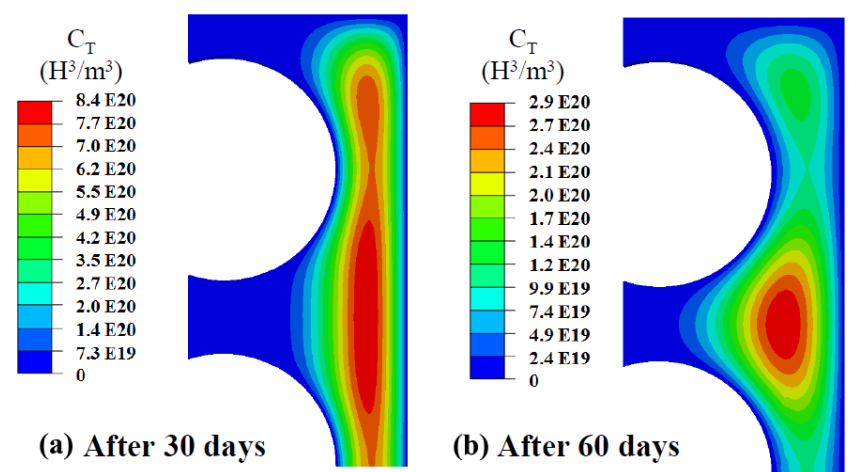

Fig. 6. Trapped tritium after 30 days (a) and 60 days (b) of the baking phase. (a) Flux after 25 days

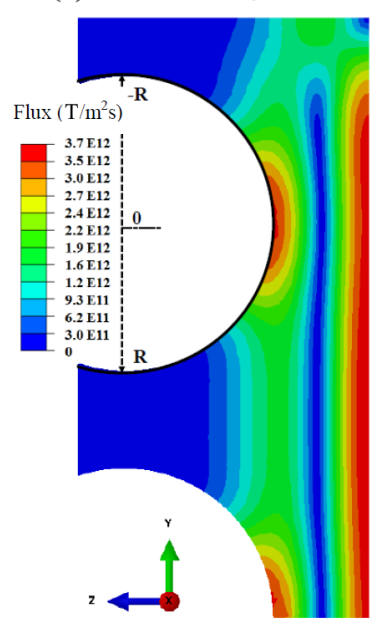

(b) Fluence along the

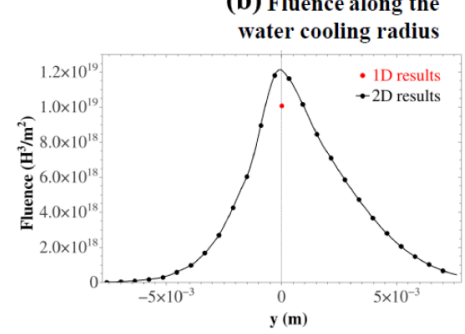

(c) Permation flux throught the radius of cooling pipe

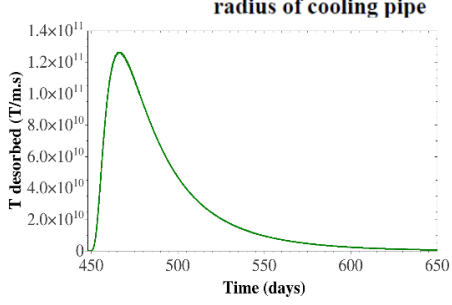

Fig. 7. After 25 days of baking phase: (a) Flux on geometry;

(b) fluence and (c) permeation flux the cooling system.

\subsection{Permeation towards the cooling water during baking}

The trapped concentration in the geometry during the baking phase is plotted on Fig. 6 (after the plasma operation): because during this phase, the temperature is uniformly imposed at $513 \mathrm{~K}$, the tritium located close to the exposed surface diffuses and becomes trapped deeper in the geometry, leading to diffusion and permeation fluxes through the cooling (Fig. 7). It is worth noting that a large amount of tritium diffused toward the exposed surface too, being then outgassed.

Permeation is significant after $12 \mathrm{~h}$, reaching a maximum for 18 days in the baking. Results of 1D/2D simulations are close at the middle of the circle $(y=0)$. However the fluence is inhomogeneous along the radius. Due to the field heterogeneities (e.g., fluence -and consequently, total fluxon the cooling system), 2D simulations are necessary to correctly predict the permeation processed during the baking phase.

\section{Mechanical fields induced by thermal expansion}

2D plane strain simulations of mechanical fields are performed by Abaqus in order to evaluate the impact of thermal dilatation on the tritium retention. The water pressure is assumed to be equal to $4 \mathrm{MPa}$. Symmetry boundary conditions are imposed everywhere except on the exposed surface.

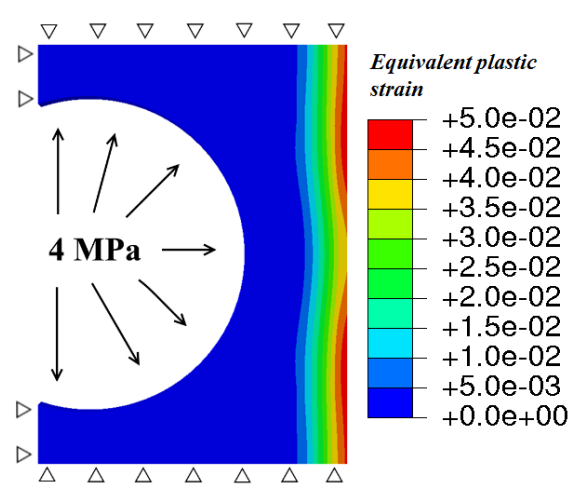

Fig. 8. Plastic strain induced by thermal expansions and pipe pressure at the end of plasma operations.

A temperature dependant Voce law with an isotropic hardening is used (derived from [37,38]) for the thermomecanical behavior, the expansions coefficient being assumed to be temperature-independent [39]. The dislocation trap density induced by the equivalent plastic strain might be estimated according to the Sofronis's law for pure iron [40]:

$$
\log N_{T}=23.26-2.33 \mathrm{e}^{-5.5 \varepsilon_{p}}
$$

where $N_{T}$ is in trap $/ \mathrm{m}^{3}$.

After the first plasma cycle the plastic strain is equal to $0.53 \%$ and next increase by around $0.3 \%$ per cycle. At the 
end of plasma operation, the maximum is $5 \%$ close to the surface exposure (Fig. 8); during baking phase, a maximum of $5.5 \%$ is reached at the cooling pipe surface. The plastic strain increase, which induce a dislocation-related trap density up to $10^{-5}$ at. fr, according to equation (4), has no impact on tritium migration in the studied configuration (this value correspond to $0.1 \%$ of the vacancy-related trap density). More computations are needed for a better evaluation of this effect, especially by accounting for kinematic hardening.

The hydrostatic pressure induces a lower $\mathrm{T}$ total retention during the plasma operations $\left(1.33 \times 10^{21} \mathrm{~T} . \mathrm{m}^{-1}\right.$ instead of $2.31 \times 10^{21}$ T.m $\left.{ }^{-1}\right): 6.35 \times 10^{20}$ T.m $\mathrm{m}^{-1}$ instead of $1.1 \times 10^{21}$ T.m ${ }^{-1}$ for the solute retention and $6.92 \times 10^{20} \mathrm{~T} . \mathrm{m}^{-1}$ instead of $1.2 \times 10^{21} \mathrm{~T} . \mathrm{m}^{-1}$ for the trap one. This is due to a global compression near the exposed surface, which modify the tritium diffusion flux [41,42], and induce a lower apparent diffusion coefficient during the loading stage. During the baking one, desorption flux towards the cooling pipe is decreased by around $24 \%$ by this pressure effect, as illustrated on Fig. 9 in which dilatational pressure fields might be observed, consequently increasing the desorption towards the exposed surface (Fig. 10).

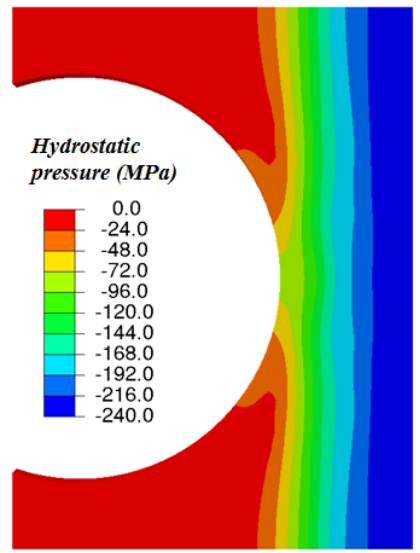

Fig. 9. Hydrostatic pressure at the beginning of the baking phase. Negative values correspond to a material dilatation.

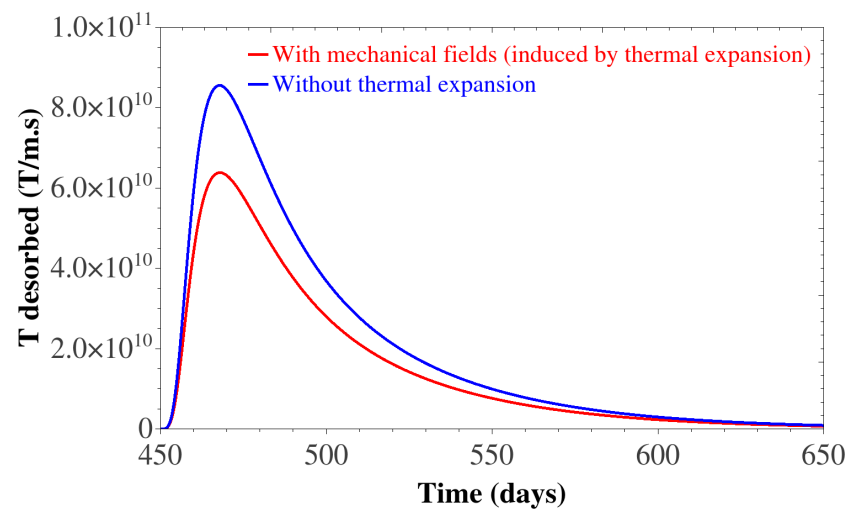

Fig. 10. T desorbed towards the cooling pipe.

\section{Conclusion}

A new set of data for tritium migration in 316L stainless steel, based on the fitting experimental works, was proposed and it is consistent with literature. The reaction-diffusion model based on the Abaqus code was applied to solve tritium retention and permeation on Diagnostic First Wall of the ITER tokamak. 1D simulations seem sufficient to model tritium behavior during the plasma operations however 2D simulations seem essential to predict correct permeation during the baking phase. Low values of traps density induced by thermal dilatation are estimated by the simulations, expecting not significant effect on tritium migration. However the hydrostatic pressure has significant effect on tritium migration which shows the value of including mechanical field resolution in simulations. Next works will be focused on the mechanical stress impacts on diffusion of hydrogen isotope through the tungsten divertor.

\section{Acknowledgements}

This work has been carried out within the framework of the EUROfusion Consortium and has received funding from the Euratom research and training programme 2014-2018 under grant agreement No 633053. The views and opinions expressed herein do not necessarily reflect those of the European Commission. The views and opinions expressed herein do not necessarily reflect those of the ITER Organization. ITER is the nuclear facility INB-174. The project leading to this publication has received funding from Excellence Initiative of Aix-Marseille University A*MIDEX, A French Investissements d'Avenir programme. This work has received funding from the French National Research Agency (Grant No. ANR-18-CE05-0012)

\section{References}

[1] Longhurst G R and Ambrosek J 2005 Verification and Validation of the Tritium Transport Code TMAP7 Fusion Sci Technol 48 468-71

[2] Sang C, Bonnin X, Warrier M, Rai A, Schneider R, Sun J and Wang D 2012 Modelling of hydrogen isotope inventory in mixed materials including porous deposited layers in fusion devices Nucl Fusion 52043003

[3] Hodille E A, Bonnin X, Bisson R, Angot T, Becquart C S, Layet J M and Grisolia C 2015 Macroscopic rate equation modeling of trapping/detrapping of hydrogen isotopes in tungsten materials J Nucl Mater 467 424-31

[4] McNabb A and Foster P K 1963 A new analysis of the diffusion of hydrogen in iron and ferritic steels Trans Metall Soc AIME 227 618-27

[5] Benannoune S, Charles Y, Mougenot J, Gaspérini M and De Temmerman G 2019 Numerical simulation by finite element modelling of diffusion and transient hydrogen trapping processes in plasma facing components Nucl Mat Ener 19 426 
[6] De Temmerman G, Hirai T and Pitts R A 2018 The influence of plasma-surface interaction on the performance of tungsten at the ITER divertor vertical targets Plasma Phys Control Fusion 60044018

[7] Simulia 2011 Abaqus Analysis User's Manual (Dassault System)

[8] Penzhorn R D, Torikai Y, Naoe S, Akaishi K, Perevezentsev A, Watanabe K and Matsuyama M 2010 Distribution and Mobility of Tritium in Type 316 Stainless Steel Fusion Sci Technol 57 185-95

[9] Penzhorn R D, Torikai Y, Watanabe K, Matsuyama M and Perevezentsev A 2012 On the fate of tritium in thermally treated stainless steel type 316L J Nucl Mater 429 346-52

[10] Guillermain D 2016 ITER Report T2YEND. Private communication.

[11] Houben A, Engels J, Rasinski M and Linsmeier C 2019 Comparison of the hydrogen permeation through fusion relevant steels and the influence of oxidized and rough surfaces Nucl Mat Ener 19 55-8

[12] San Marchi C, Somerday B P and Robinson S L 2007 Permeability, solubility and diffusivity of hydrogen isotopes in stainless steels at high gas pressures Int J Hydrog Energy 32 100-16

[13] Doyle B L and Brice D K 1987 The influence of displacement damage on deuterium permeation in 316 stainless steel $\mathrm{J} \mathrm{Nucl}$ Mater 145-147 288-91

[14] Shan C, Wu A and Chen Q 1991 The behavior of diffusion and permeation of tritium through $316 \mathrm{~L}$ stainless steel $J \mathrm{Nucl}$ Mater 179-181 322-4

[15] Tanabe T, Yamanishi Y, Sawada K and Imoto S 1984 Hydrogen transport in stainless steels J Nucl Mater 1231568 72

[16] Forcey K S, Ross D K, Simpson J C B and Evans D S 1988 Hydrogen transport and solubility in $316 \mathrm{~L}$ and 1.4914 steels for fusion reactor applications $J$ Nucl Mater 160 117-24

[17] Reiter F, Alberici S, Camposilvan J, Serra E, Forcey K S and Perujo A 1993 Diffusivity and Solubility of Hydrogen Isotopes in the Martensitic Steel DIN 1.4914 (MANET) after Thermal Exposure at $900 \mathrm{~K} Z$ Phys Chem 181 151-7

[18] Grant D M, Cummings D L and Blackburn D A 1988 Hydrogen in 316 steel - diffusion, permeation and surface reaction J Nucl Mater 152 139-45

[19] Li Y Y and Xing Z S 1989 Effect of hydrogen on the microstructure, mechanical properties and phase transformations in austenitic steels $J$ Nucl Mater 169 151-7

[20] Austin J H and Elleman T S 1972 Tritium diffusion in 304and 316-stainless steels in the temperature range 25 to $222^{\circ} \mathrm{C}$ J Nucl Mater 43 119-25

[21] Hirabayashi T and Saeki M 1984 Sorption of gaseous tritium on the surface of type 316 stainless steel J Nucl Mater 120 $309-15$

[22] Reiter F, Camposilvan J, Caorlin M, Saibenea G and Sartoria R 1985 Interaction of Hydrogen Isotopes with Stainless Steel 316 L Fusion Technol 8 2344-51

[23] Kishimoto N, Tanabe T, Suzuki T and Yoshida H 1985 Hydrogen diffusion and solution at high temperatures in $316 \mathrm{~L}$ stainless steel and nickel-base heat-resistant alloys $J \mathrm{Nucl}$ Mater 127 1-9
[24] Hashimoto E and Kino T 1985 Hydrogen permeation through type 316 stainless steels and ferritic steel for a fusion reactor $J$ Nucl Mater 133-134 289-91

[25] Sugisaki M, Furuya H, Ueki H and Ejima S 1985 Surface reaction and bulk diffusion of tritium in SUS-316 stainless steel J Nucl Mater 133-134 280-3

[26] Langley R A 1984 Hydrogen trapping, diffusion and recombination in austenitic stainless steels $J$ Nucl Mater 128$129622-8$

[27] Doyle B L and Brice D K 1984 Steady state hydrogen transport in solids exposed to fusion reactor plasmas, part II: Applications of theory $J$ Nucl Mater 123 1523-30

[28] Wilson K L and Baskes M I 1978 Deuterium trapping in irradiated 316 stainless steel $J$ Nucl Mater 76-77 291-7

[29] Charles Y, Nguyen T H and Gaspérini M 2017 FE simulation of the influence of plastic strain on hydrogen distribution during an U-bend test Int J Mech Sci 120 214-24

[30] Charles Y, Nguyen T H and Gaspérini M 2017 Comparison of hydrogen transport through pre-deformed synthetic polycrystals and homogeneous samples by finite element analysis Int J Hydrog Energy 42 20336-50

[31] Benannoune S, Charles Y, Mougenot J and Gaspérini M 2018 Numerical simulation of the transient hydrogen trapping process using an analytical approximation of the McNabb and Foster equation Int J Hydrog Energy 43 9083-93

[32] Vasikaran E, Charles Y and Gilormini P 2019 Implantation of a reaction-diffusion Process in Abaqus software Mech Indus

[33] Longhurst G R 1985 The soret effect and its implications for fusion reactors J Nucl Mater 131 61-9

[34] Ueda Y, Schmid K, Balden M, Coenen J W, Loewenhoff T, Ito A, Hasegawa A, Hardie C, Porton M and Gilbert M 2017 Baseline high heat flux and plasma facing materials for fusion Nucl Fusion 57092006

[35] Hodille E A, Fernandez N, Piazza Z A, Ajmalghan M and Ferro Y 2018 Hydrogen supersaturated layers in H/D plasmaloaded tungsten: A global model based on thermodynamics, kinetics and density functional theory data Phys Rev Mater 2 093802

[36] Ogorodnikova O V, Zhou Z, Sugiyama K, Balden M, Pintsuk G, Gasparyan Y and Efimov V 2017 Surface modification and deuterium retention in reduced-activation steels under lowenergy deuterium plasma exposure. Part II: steels predamaged with $20 \mathrm{MeV}$ W ions and high heat flux Nucl Fusion $\mathbf{5 7} 036011$

[37] Johnson G R and Cook W H 1983 A constitutive model and data for materials subjected to large strains, high strain rates, and high temperatures Seventh International Symposium on Ballistics ed American Defense Preparedness AssociationKoninklijk Instituut van Ingenieurs (Netherlands) (Hague, Netherlands) pp 1-7

[38] Umbrello D, M'Saoubi R and Outeiro J C 2007 The influence of Johnson-Cook material constants on finite element simulation of machining of AISI 316L steel Int J Mach Tool Мапи 47 462-70

[39] Sayman O, Sen F, Celik E and Arman Y 2009 Thermal stress analysis of $\mathrm{Wc}-\mathrm{Co} / \mathrm{Cr}-\mathrm{Ni}$ multilayer coatings on $316 \mathrm{~L}$ steel substrate during cooling process Mater Des 30 770-4 
[40] Sofronis P and McMeeking R M 1989 Numerical analysis of hydrogen transport near a blunting crack tip $J$ Mech Phys Solids 37 317-50

[41] Krom A H M, Koers R W J and Bakker A D 1999 Hydrogen transport near a blunting crack tip J Mech Phys Solids $\mathbf{4 7}$ 971-92

[42] $\mathrm{Hu}$ A and Hassanein A 2014 Modeling hydrogen isotope behavior in fusion plasma-facing components $J$ Nucl Mater $44656-62$ 